\title{
Decrease of cold-formed slotted studs heat conductivity by slots shape modification
}

\author{
Rafik Alekperov ${ }^{*}$ and Ivan Aksenov ${ }^{\dagger}$ \\ Moscow State University of Civil Engineering, Yaroslavskoe shosse, 26, Moscow, 129337, Russia
}

\begin{abstract}
Cold-formed steel framing is gaining ground in Russia. Now it's making attempts to adopt curtain wall panels with cold-formed slotted steel members in residential building. In view of cold Russian climate, a problem of mitigation of the cold bridge effect created by the steel have appeared. It's proposed to improve steel members' thermal performance by choice a new web holes shape. Stud models with different web holes configuration were investigated by means of fine element analysis in COMSOL Multiphysics software. Their thermal and load-carrying performance was compared with a standard slotted stud. Two promising pilot models were chosen for further experimental research. An experiment to compare heat conduction capacity of these pilot models and a standard slotted stud was carried out in the Laboratory of glass and facade constructions. The results of this experiment are presented in this article.
\end{abstract}

\section{Introduction}

\subsection{A brief history review of cold-formed framing}

For the first time cold-formed framing was used in building in America in the mid-19th century. It was the time of the California Gold Rush when enterprising people moved to Coloma in search of the precious metal. They needed cheap and fast-erected houses they could live in. Peter Naylor, a roofer from New York, constructed such a house. He advertised a portable house for California, with components made of cold-formed steel. It was cheaper than a wooden house and could be built in a day. Since that time and until the World War II there were not many attempts to use cold-formed framing for building. In the 1940-ies the two following things changed that situation: a design standard for cold-formed steel was created by The American Iron and Steel Institute (the first edition in 1946) [1]; it became necessary to provide GIs returning from the war with dwelling. The second thing urge Carl Strandlund, a businessman and a founder of Lustron Homes, on development prefabricated enamelled steel houses. Altogether 2498 of them were sold between 1946 and 1948 [2].

At the same time that the use of cold-formed steel framing was gaining momentum the gypsum board industry was growing. Developing from the moment of its patenting in 1894

\footnotetext{
* Corresponding author: 5187132@gmail.com

† Corresponding author: ivanak1995@mail.ru
} 
the gypsum board became widely used in the mid-20th century. At that moment the gypsum companies had one concern - to develop a light non-combustible system of partitions with gypsum boards for using in high-rise buildings, and steel framing appeared to be the answer. It took some time to find the perfect solution for fastening gypsum boards to steel studs. Eventually, it was self-drilling screws. These screws as well as development of tools to drive them provide a wide opportunity for steel framing in a commercial market.

The subsequent evolution of steel framing went on the way of unification and standards specification [3]. In 1990-ies a single catalogue for cold-formed steel members was created and it is steel developing. The AISI standards have had nine editions since 1946 with the last in 2001 (with 2004 addendum). European Committee or Standardization released in 1997 the «Eurocode 3: Design of Steel Structures - General Rules Supplementary Rules for Cold-Formed Thin Gauge Members and Sheeting» that forms the ground for cold-formed steel framing application in European countries. In the 21 st century the cold-formed steel framing has become a recognized building system.

\subsection{The scope of the study}

Nowadays cold-formed steel framing is widely used in USA, Canada, Mexico, New Zealand, Austria, Finland, France, the Netherlands, Great Britain, Sweden etc. Thus, the part of it in construction fund reaches $15 \%$ in USA, $20 \%$ in Great Britain, 15\% in Sweden, $10 \%$ in Canada. It is growing in Russia as well $[4,5]$.

One new feature of thin-wall steel members had appeared since they are used in countries with a quite cold climate. In such countries as Sweden, Finland and Russia the problem of energy conservation becomes highly important. In order to minimize heat migration through the cold bridge thermally efficient studs with slotted webs have been designed (figure 1) [6]. These studs are manufactured on a roll forming machine from a galvanized steel plate. After forming a section, a perforation unit makes slits in its web and then cutting device cut the product into pieces of required length [7].

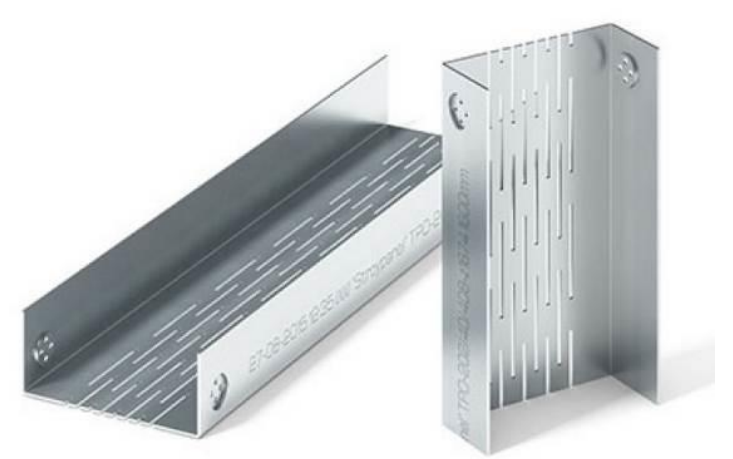

Fig. 1. A thermal efficient slotted stud. Available at: https://slp.su/produktsia/profililstk/thermoprofile-lstk-tpn-100-12

There are several construction methods for cold-formed framing [8]:

1. 'stick-build' construction method when discrete steel members are assembled on site;

2. panel construction method when floor cassettes, wall panels and roof trusses are prefabricated in a factory and deliver on site;

3. modular construction method when building units are entirely prefabricated in a factory and deliver on site; 
The most promising method to use thermal efficient slotted sections in residential building in Russia is the panel construction method. There are attempts to adopt curtain light steel wall panels in block of flats building. These prefabricated panels are fastened to reinforced concrete floor slabs via steel brackets. Thermal performance of such panel pilot models was tested in the Laboratory of glass and facade constructions in National Research Moscow State University of Civil Engineering (NRU MGSU). By means of the test bench KS $3025 / 650$ a temperature difference on either model's side was created: $22^{\circ} \mathrm{C}$ on the internal side (the rated temperature in living space [9]) and $-20^{\circ} \mathrm{C}$ on the external side (close to the rated external temperature of $-25^{\circ} \mathrm{C}$ for winter in Moscow [10]), that allowed to measure thermal resistance of different model areas. The research showed that heat migration through the areas with thin-wall steel members is overly high. The offer to use 2 $\mathrm{cm}$ extruded polystyrene layer (placed between steel members and inner gypsum sheeting) was made. The problem was solved by this additional thermal insulation but it also brought to the question if it's possible to decrease the cold bridge effect by modification steel members themselves. The vast majority of thin-wall slotted studs has web holes with the shape of thin rectangle. The vast majority of thin-wall slotted studs has web holes with the shape of thin rectangle. A literature review revealed that there are no researches with an attempt to find a new (more thermal efficient) shape of these holes. The most closely related one was a research made in Poltava National Technical Yuriy Kondratyuk University (Ukraine). It considers a slots' configuration (a number of slot rows, a displacement of these rows relative to each other, a slot proximity) influence on a steel member thermal conductivity, but this article doesn't consider the influence of a slot shape itself [11].

\subsection{The object of the study}

The aim of this study is to find a new web hole shape of thin-wall steel members, which would lead to thermal conductivity reduction of these members in comparison with existing slotted variant and won't decrease their load-carrying capacity. The study is conducted on the example of 150x50x1.2 mm C-shape stud (figure 2).

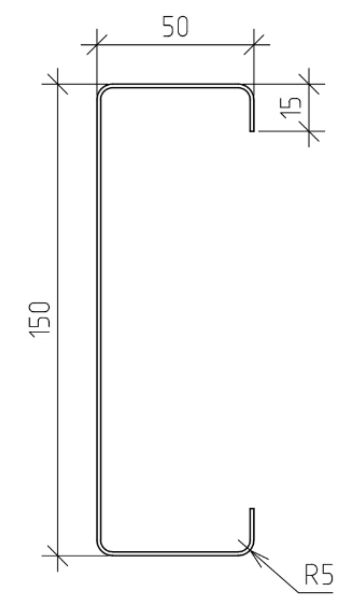

Fig. 2. The C-shape section investigated in the study 


\section{Theoretical investigation}

From the beginning the theoretical investigation was made by fine element analysis in COMSOL Multiphysics software. A 3D model of a real slotted stud was made in the program (figure 3a). Its load-carrying and heat conduction capacity was determined and used as the standard, new models were compared with. All models had the section showed in figure 2 were $3 \mathrm{~m}$ length and differed only in web holes shape. A parametric study in COMSOL allowed to test studs with great amount of different web holes shape. Two models demonstrated good results and were chosen for a further experimental research (figure $3 b-c)$.

a

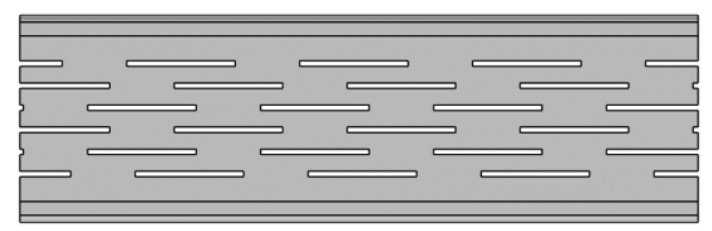

b

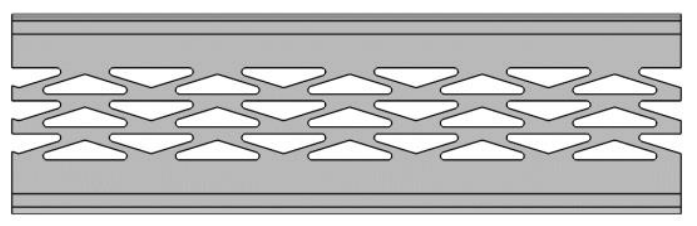

c

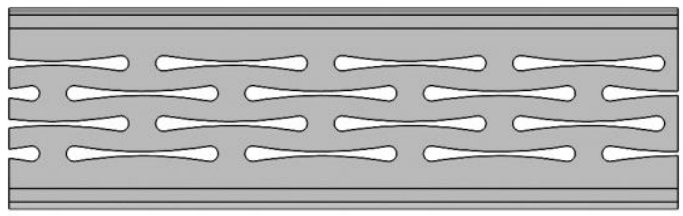

Fig. 3. New studs' models: $a$ - standard slotted stud; $b$ - stud with a triangular holes shape (St1), $c$ - stud with a dumbbells-like holes shape (St2)

\subsection{Determination of studs' thermal performance}

To estimate stud heat conductivity the following problem statement was used: as boundary conditions the constant temperature (of $20^{\circ} \mathrm{C}$ and $21^{\circ} \mathrm{C}$ ) was established on outer surface of either stud flanges and the condition of zero heat flux was established on the rest of boundaries. The stud inner volume was completely filled with mineral wool (figure 4).

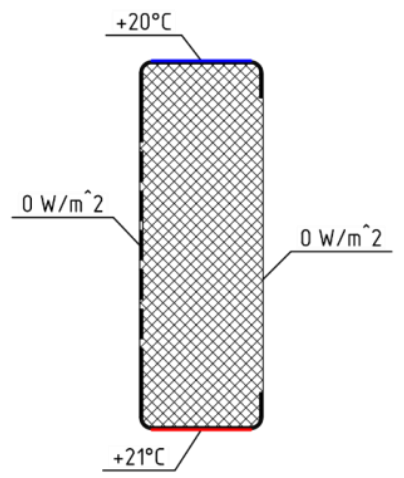

Fig. 4. A heat transfer problem statement 
An integral value of heat flux $(\mathrm{H}, \mathrm{mW})$ passing through the flange (through the face with a constant temperature) displayed the thermal characteristic of a stud. The higher this value is, the better a stud conducts heat. The results of calculation for different models are shown in table 1 .

Table 1. Thermal performance of the models

\begin{tabular}{|l|c|c|c|c|}
\hline A stud model & H, $\mathbf{~ m W}$ & Rel. value of $\mathbf{H , ~ \%}$ & Volume, $\mathbf{c m} 3$ & Rel. volume value, $\%$ \\
\hline Slotted stud & 265 & 100 & 909 & 100 \\
\hline St1 & 216 & 82 & 829 & 91 \\
\hline St2 & 226 & 85 & 889 & 98 \\
\hline
\end{tabular}

In figure 5 isothermal lines show a temperature distribution on outer surface of 3D models for each investigated stud. In this figure metal and mineral wool are denoted with different colours. There are 20 isolines in each model. As it could be seen, holes in new models don't slot a web entirely. An explanation for it will be given later.
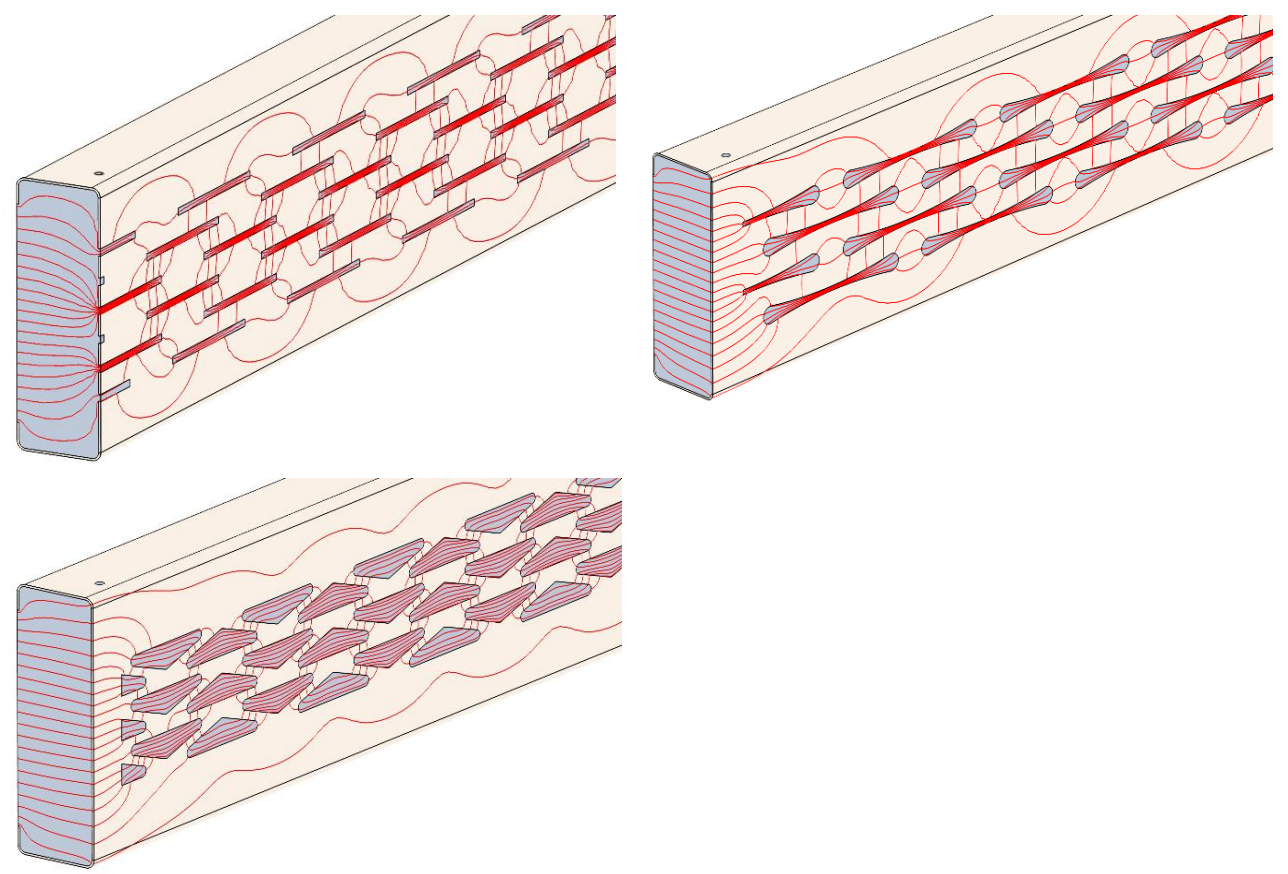

Fig. 5. Isothermal lines display a temperature distribution on outer 3D models surfaces

\subsection{Determination of studs' load-carrying performance}

For strength calculation it's very important to make up a design scheme correctly. The mechanical work of studs is considered in the context of curtain wall panels, a typical design of which presents a metal frame with thermal insulation between its elements. The frame consists of C-shape studs and channel-shape tracks [12]. It's sheathed with gypsum boards on one side and different cladding on the other (sheeting, board ore rendered materials, cement plates, etc.) [13]. All frame elements are joined with special self-drilling screws. As it was said, the panels are fastened to floor slabs via steel brackets. Brackets are 
placed at stud-track junctions. Thus, the frame members have the following mechanical work conditions:

1. The top and the button tracks are fastened to floor slab via brackets;

2. Studs are fastened to the top and the button tracks

So, in the simplest form a stud has the fixing conditions listed below.

Its upper and lower ends are putted into tracks and fastened to them with screws (figure 6). This connection can be considered as a hinged one. The stud is able to rotate in a wall plane as well as in the plane perpendicular to a wall (due to tracks torsion), but it can't rotate around its axis.

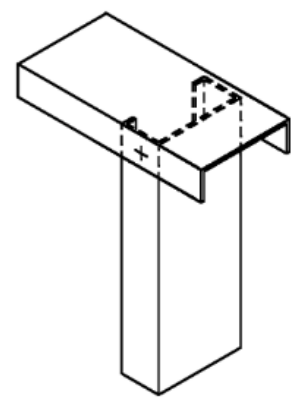

Fig. 6. A stud-track connection

A sheeting which is attached to the frame member on both sides constrains stud flanges movement along the wall surface.

The major load acting on the wall panel is a wind pressure applied on the stud flanges. It should be noticed that when a stud is bended in the web plane a web appears in the position with the smallest compression/tensile stresses. Because of this, there are no special restrictions on web holes shape associated with a possible web local buckling [14].

In COMSOL Multiphysics boundary conditions correspondent to a real mechanical stud work were implemented. On the stud ends (at the $25 \mathrm{~mm}$ distance from the butt-ends) in both flanges $\mathrm{d} 5 \mathrm{~mm}$ holes were made, simulating screw connection holes. The inner surfaces of the opposite holes were rigidly connected with the imaginary non-deformable cylindrical surface (in figure 7 the imaginary cylinder, for clarity, is represented by a real object).

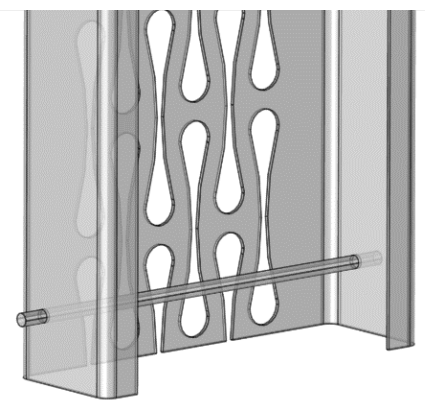

Fig. 7. Simulation of stud ends fastening

This cylinder is pivotally fixed in its geometric centre, at that it can't rotate around the stud axis (in the other two directions it can rotate freely). 
The boundary condition created by an internal and external wall sheathed was implemented via preventing points of outward flanges surfaces from moving along the wall in the horizontal direction.

A distributed load, causing a stud bend, was applied to an outward flange surface.

There are different standards in Russia that specify requirements for material coldformed steel members are made of. It can be galvanized low carbon sheet steel according the GOST 14918-80 [15]. This standard determines the minimum steel yield stress of 230 $\mathrm{MPa}$ [16]. In a mechanic simulation a simplified model of stress-strain low carbon steel behaviour was used, the stress-strain dependence for this model is shown in figure 8.

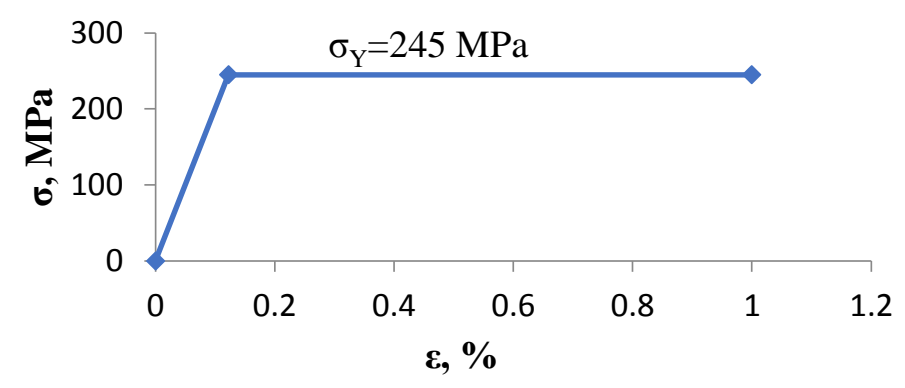

Fig. 8. A stress-strain diagram

In calculation the Mises plasticity condition was used, geometric non-linearity of models' deformation was also taken into account. The calculation was made for a load gradually increased from zero to a threshold value with a constant step. Herewith, the following picture was observed: first, the material yield point was reached in the screw connection node (with a load $\mathrm{F}_{1}$ ), with a further load increase the area of plastic deformations in the screw node grew and with a load equal to a certain value $F_{2}>F_{1}$ plastic deformations appeared in the web support area between slots.

Critical load values for the stud models are shown in table 2.

Table 2. The load-carrying performance of the models

\begin{tabular}{|l|c|c|c|c|}
\hline \multicolumn{1}{|c|}{ A stud model } & $\mathbf{F 1}, \mathbf{k N} / \mathbf{m} 2$ & Rel. value of F1, \% & $\mathbf{F 2 , ~} \mathbf{k N} / \mathbf{m} 2$ & Rel. value of $\mathbf{F 2 , ~} \%$ \\
\hline Slotted stud & $4.0-4.6$ & 100 & $17.2-17.8$ & 100 \\
\hline St1 & $4.6-5.2$ & $\approx 114$ & $25.0-25.6$ & $\approx 145$ \\
\hline St2 & $4.6-5.2$ & $\approx 114$ & $21.4-22.0$ & $\approx 124$ \\
\hline
\end{tabular}

As it can be seen, the first critical load for the models are almost the same. The second critical load for the new models is $24-45 \%$ higher than for the slotted one. This is due to a new method proposed for web holes formation.

Plastic deformations in a web supported area appear as a result of a shear. A great importance at that has a size of overhanging free web parts arise at butt-ends as a result of stud cutting at a factory. Existing web slots formation method doesn't take into account the place where a billet is cut to form studs with a required length. It is proposed to change this method. A web holes pattern should break in the place of billet cutting, which will significantly increase stud shear resistance in supported area (figure 9 and 10). 


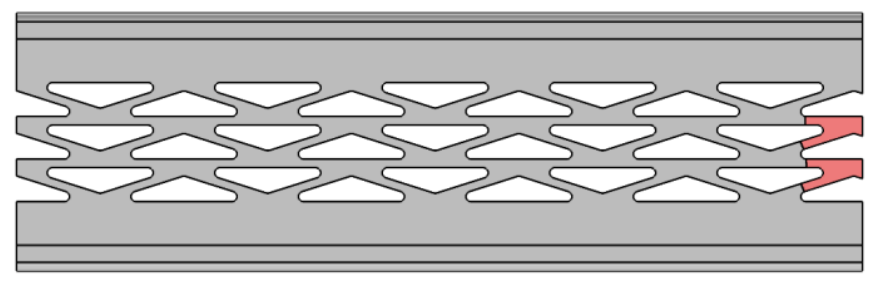

Fig. 9. Overhanging web pars

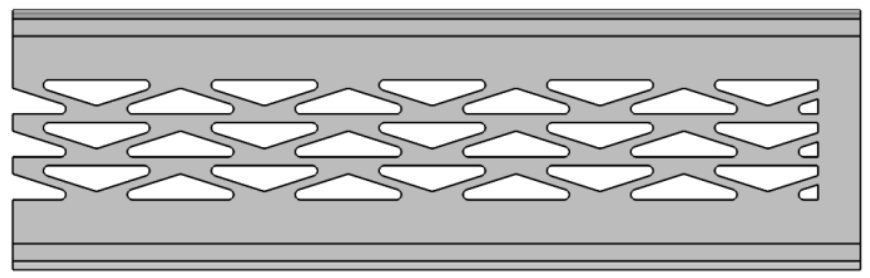

Fig. 10. Strengthening of a web supported area: the holes pattern broken in the place of billet cutting

\subsection{Results}

By means of fine element analysis in COMSOL Multiphysics two stud models with new web holes shape were developed. Thermal and load-carrying performance of these new models are better than the standard slotted stud has (table 3). A new web holes formation method, that increase a stud web shear resistance, was proposed. A heat conductivity of new models was determined with taking into consideration this web strengthening.

Table 3. A summary comparison table.

\begin{tabular}{|c|c|c|c|c|}
\hline A stud model & $\mathbf{H}, \mathbf{m W}$ & Volume, $\mathrm{cm} 3$ & $\mathrm{~F} 1, \mathrm{kN} / \mathrm{m} 2$ & $\mathrm{~F} 2, \mathrm{kN} / \mathrm{m} 2$ \\
\hline Slotted stud & 265 & 909 & $4.0-4.6$ & $17.2-17.8$ \\
\hline St1 & 216 & 829 & 4.6-5.2 & $25.0-25.6$ \\
\hline St2 & 226 & 889 & 4.6-5.2 & $21.4-22.0$ \\
\hline
\end{tabular}

\section{Experimental investigation}

Real specimens of the developed models were manufactured and an experiment to compare their thermal performance with a standard slotted stud was conducted in the Laboratory of glass and facade constructions in National Research Moscow State University of Civil Engineering. To carry out the experiment a test panel was assembled. It presented a timber frame with three studs (the standard, St1, St2) installed in it. Space between the studs was filled with mineral wool, the frame was sheathed with gypsum board on both side (figure 11). This panel was installed on a test bench, which lower temperature from one side of the panel to $-18^{\circ} \mathrm{C}$. 

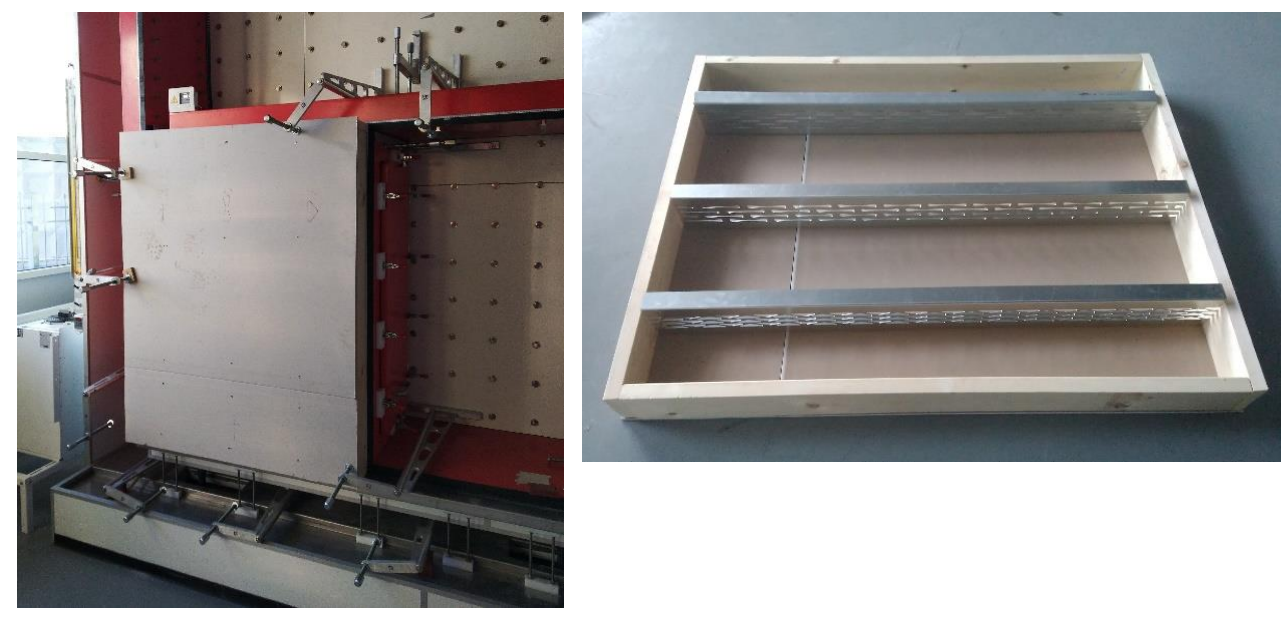

Fig. 11. The test panel assembled for the experiment.

To measure a thermal resistance of the structure at stud location the heat flux measuring device ITP-MG "POTOK" was used. Contact temperature sensors were placed pairwise (tow to each stud) on either panel sides at one altitude and heat flux sensors were placed on the warm panel side near temperature sensors (figure 12). The used heat flux measuring method comply to GOST 25380-2014 requirements [17].

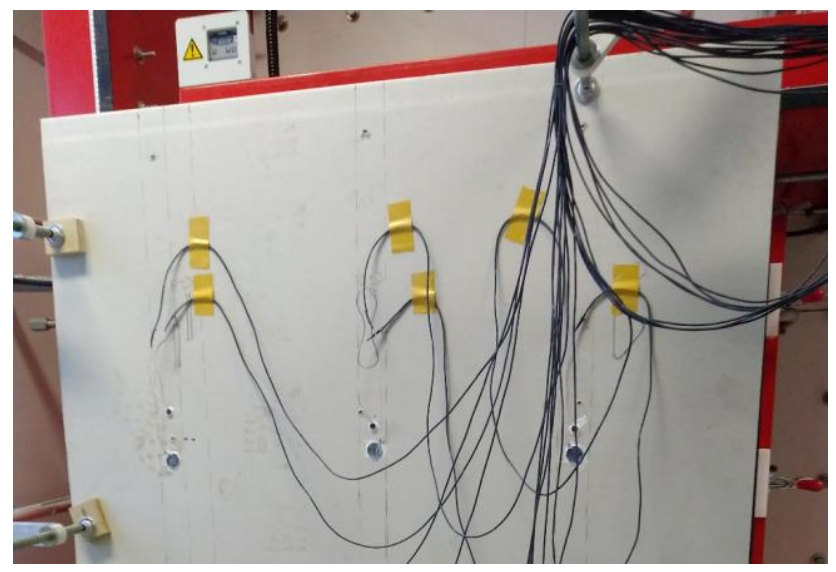

Fig. 12. Sensors layout

After stationary heat flux was established, recording of sensor readout was launched (with minute interval). This recording lasted for 3 hours, then an obtained data fed into computer and averaged. On the basis of these averaged data, the thermal resistance values for each stud were calculated (table 4).

Table 4. Average sensors readouts and calculated heat transfer coefficients of the studs

\begin{tabular}{|l|c|c|c|c|c|}
\hline $\begin{array}{c}\text { A stud } \\
\text { model }\end{array}$ & $\begin{array}{c}\text { Av. temp. on } \\
\text { opposite sides, }{ }^{\circ} \mathbf{C}\end{array}$ & $\begin{array}{c}\text { Temp. } \\
\text { diff., }{ }^{\circ} \mathbf{C}\end{array}$ & $\begin{array}{c}\text { Av. heat flux, } \\
\mathbf{W} / \mathbf{m} 2\end{array}$ & $\begin{array}{c}\mathbf{U}, \\
\text { W/ } \mathbf{m}^{\circ}{ }^{\circ} \mathbf{C}\end{array}$ & $\begin{array}{c}\text { Rel. value of U, } \\
\%\end{array}$ \\
\hline Sl. stud & $+19.0 /-13.8$ & 32.8 & 33.15 & 1.01 & 100 \\
\hline St1 & $+19.3 /-17.1$ & 36.4 & 29.98 & 0.82 & 81 \\
\hline St2 & $+19.1 /-16.9$ & 36.0 & 33.01 & 0.92 & 91 \\
\hline
\end{tabular}




\section{Summary}

The experiment results confirmed the theoretical ones. It was found out, that the cold bridge effect for developed studs is $9-19 \%$ less, then for the standard slotted stud. The St1 specimen (with the triangular web holes shape) turned out to be the most thermal effective. The results showed that the way to improve thermal performance of cold-formed steel members by web holes modification is promising. It precludes the need to complicate a wall panel design by adding additional thermal insulation layer. Also, the new web holed formation method is proposed. At a cold-formed steel members' fabrication a web holes pattern should break in the place of billet cutting. This will significantly increase steel member shear resistance in supported area and won't influence much on their thermal conductivity.

\section{References}

1. Specification for the Design of Light Gage Steel Structural Members, AISI, 1946

2. R. Thornton Lustron Homes, Part 1 [Online]. Available: http://www.oldhouseweb.com/architecture-and-design/lustron-homes-part-1.shtml (2006)

3. Y. Wei-Wen, Ph. D. and P. E. Cold-Formed Steel Design, 3d ed (New York: John Wiley \& Sons, Inc., 2000)

4. E. N. Zhmarin J. Constr. of Unique Build. and Str. 2 pp 27-30 (2012)

5. V. Yakubson Civil Eng. J. 6 2-3 (2009)

6. M. Veljkovic and B. Johansson Thin-Wall Str. 441272 - 79 (2006)

7. A. I. Alhimenko, N. I. Vatin and V. A. Ribakov Light steel thin-walled structures technology (Saint-Petersburg, 2008)

8. P. J. Grubb, M. T. Gorgolewski and R. M. Lawson Building Design using Cold Formed Steel Sections. Light Steel Framing in Residential Construction (Berkshire: The Steel Construction Institute, 2001)

9. Residential and public buildings. Microclimate parameters for indoor enclosures, GOST 30494-2011, Standardinform, 2013

10. Building climatology, SP 131.13330.2012, Ministry of building of Rissia, 2015 (in Russian)

11. V. V. Cherniavsky, V. O. Semko, O. I. Urin and D. A. Prohorenko Ac. J. Industrial Machine Building, Civil Eng. 1 194-199 (2011)

12. Low-Rise Residential Construction. Details. North American Steel Framing Alliance, 2000

13. P. V. Semikin and V. N. Doljikov Creativity And Modernity 1 65-76 (2016)

14. Z. H. Zabelian Ind. \& Civ. Constr. 217 - 23 (2015)

15. N. I. Vatin and E. N. Popova Slotted sections in light steel constructions (SaintPetersburg, 2006)

16. Continuously galvanized sheet steel. Specifications, GOST 14918-80, Standardinform, 2007

17. Buildings and structures. Method of measuring density of heat flows passing through enclosing structures, GOST 25380-2014, Standardinform, 2015 